\title{
Default Diminutives: Evidence from Modern Standard Arabic
}

\author{
Sabri Alshboul \\ Department of English language, literature and cultural studies, Hashemite University, P.o.Box:330127, Postal Code \\ 13133, Zarqa, Jordan \\ Sahail M. Asassfeh \\ Department of English language, literature and cultural studies, Hashemite University, P.o.Box:330127, Postal Code \\ 13133, Zarqa, Jordan \\ Yousef Al shaboul \\ Department of English language, literature and cultural studies, Hashemite University, P.o.Box:330127, Postal Code \\ 13133, Zarqa, Jordan
}

\begin{abstract}
Different approaches to inflectional morphology converge on the notion that default inflection is computed through a combinatorial mechanism. The current study explores the mechanism of defaultness which makes an inquiry for the emergence of the diminutive plural inflection as a default form taking the suffix - aat in Modern Standard Arabic (MSA). The findings of this study showed that there is a role displayed by the "canonical root" in the formation of this default form thus the wide application of the default inflection results from the fact that the default inflection applies to mental variables which are abstract labels 'VERB or NOUN' (Berent 1999, Kim et al 1991, 1994 and Marcus et al 1995). Further, this study replicated previous studies on English and Hebrew (Berent: 1999) in maintaining the insensitivity of defaultness to similarity effects.
\end{abstract}

Index Terms - default, canonical root, similarity effects, diminutives, sound feminine plural

\section{INTRODUCTION}

Investigations on inflectional morphology have been the subject of much debate between the associative accounts of cognition presented by Rumelhart \& McClelland (1986), McWhinny \& Leinbach (1991), Plunkett \& Marchmann (1993) Stemberger (1998); and Bybee (1995) and the symbolic accounts stated by Pinker and Prince (1988), Marcus et al(1992), Marcus et al (1995) Clahsen (1996); and Pinker (1998). Both theories converge on the proposal that irregular inflection is achieved by associative memory, while the difference between them is in their treatment of regular default inflection. According to the associative-single mechanism model, both regular and irregular forms are processed in the associative memory, hence explicable by associations between specific token and type frequencies. Bybee (1995) also provides accounts for this proposal in the schema model of inflection treatment. On the other hand, proponents of the symbolic model attribute the default regular inflection to a symbolic combinatorial process working over variables which lack canonical roots. The current study examines these accounts of inflectional morphology using evidence from the diminutive forms observed in Modern Standard Arabic (hence MSA). In this study, we will argue that the plural of the diminutive forms in MSA is expected to provide evidence on the architecture of the MSA lexicon in terms of the defaultness representation.

\section{The PluRAL System IN MSA}

There are two distinct classes of plural inflection observed in MSA: the sound plurals and broken plurals. The sound plurals are formed in a concatenative mechanism by adding either the suffix -aat to the singular form to make the sound feminine plural (e.g. maktaba/maktab-aat 'a library/libraries') or the suffix -uun to the singular form to make the sound masculine plural (e.g.saa?iq/saa?ig-uun 'a driver/drivers). McCarthy and Prince (1990, p. 212) state that the sound feminine plural is systematically found with the following: proper names; transparently derived nouns or adjectives such as participles, deverbals, and diminutives, noncanonical or unassimilated loans (keibil /keibl-aat 'a cable/cables); and the names of the letters of the alphabet which are mostly noncanonical. On the other hand, broken plurals are formed by a hierarchical non-concatenative process. McCarthy \& Prince (1990) also provide evidence that the broken plural usually has the same consonants (root) as the singular form but vowels are inserted between the consonants in accordance with a strict pattern or template For example, the singular kur.si 'a chair' $C V C$. $C V$ word maps to the plural ka.raa.si 'chairs'; the plural template in this case being CaCaaCi. Wright (1995) indicates that Arabic contains 31 broken plural templates and these broken plural templates constitute the major process of plural formation in Arabic. 


\section{Defaultness IN MSA}

The mechanism of defaultness to be investigated in this research makes inquiry for the emergence of the diminutive plural inflection as a default form taking the suffix - aat in MSA and the role displayed by the notion "canonical root" in the formation of this default form. Marcus (1998 \& 1999) Pinker and Prince (1988) in their accounts of the symbolic model made clear that the wide application of the default inflection results from the fact that the regular inflection applies to mental variables which are abstract labels 'VERB or NOUN'. Marcus (1995) views 'defaultness' as an operation which applies not to particular sets of stored items or to their frequent patterns, but to any item whatsoever, as long as it is not listed in the lexical memory. This item may be unfamiliar, dissimilar to familiar items or computationally inaccessible because of noise in memory or because of the way the data in memory is structured. Corbett (1994), on the other hand, deals with defaults rather than "markedness" since defaults are language specific, while "marked" is universal. Based upon our assumptions, the notion of "defaultness" is an indispensable mechanism to account for the lexical status of the nominal system (i.e. diminutive forms) in MSA.

Berent (1999) Kim et al (1991 \& 1994) and Marcus et al (1995) provide ample evidence that the regular inflection as a default (the sound feminine with the suffix -aat in our case) can be observed with the inflection which is assigned to borrowings, names, and denominals in English and Hebrew, all of which fail to trigger default irregular patterns as a stored association, because these default forms lack a canonical root. Prasada and Pinker (1993) show that according to the symbolic account, default inflection could also apply to non-words that are dissimilar to English forms, hence are unlikely to activate stored irregular tokens. In terms of the irregular inflection, this account has the same application observed with the distribution asymmetry account. This account is motivated by the argument that the irregular forms are tightly bounded, and thus new words take similar inflection to these clustered ones and if blocked the default regular inflection is applied.

Moreover, the purpose of this research is to articulate the following predictions. The symbolic account can be maintained to deal with the plural forms of diminutive forms to define 'defaultness' in MSA. The symbolic approach assumes a single-default rule system for the grammar, which follows from an exclusive reliance on the 'elsewhere' principle. The current research aims at exploring the representation of the default system of the diminutives in the plural forms of the Modern Standard Arabic (MSA). This representation is expected to account for the status of the derived forms (the diminutive forms in our case) that take the sound feminine marker - aat to denote the plural inflection as a default form due to the lack of the canonical root (more articulation on the notion of canonical root account to be introduced in the body of this research). Our analysis would take into account the fact that the emergence of the default forms with the diminutive forms is not subject to similarity effects.

\section{A. The Sound Feminine Default in MSA: Diminutives}

The category of derived nouns includes diminutives and derivatives or participles, which are formed from other words by rules of morphological derivation. For instance, the existence of a verbal noun presupposes the existence of a verb from which it is derived. Derived nouns in MSA -diminutives in particular- have the property of having a default inflection in the plural. According to the data displayed below, our assumption is that the diminutive forms take the sound feminine plural (-aat) due to the fact that these forms -when derived- have no canonical root; hence they have no access to the lexicon of MSA and thus fall into the "elsewhere" category or outside the phonological space.

Ratcliffe (1998) and Wright (1995) indicate that a diminutive form like what is shown in data set (1) in MSA is formed from a noun by inserting the short vowel $\boldsymbol{u}$ after the initial consonant; the diphthongized sound $\boldsymbol{a y}$ after the second consonant and the long vowel $\boldsymbol{e} e$ after the third if the word has a quadrilateral root. For example, Wright (1995) and Khouloughli (1992) provide data on the collective noun waraq 'paper' and its plural waraqat 'pieces of paper', we have wuraygaat 'little pieces of paper', for instance. The singular word, juz? 'a part' has the iambic broken plural? ajzaa? 'parts' whereas its diminutive juzay? 'a molecule' has the sound-feminine plural juzay?-aat 'molecules'.

Diminutives in MSA provide converging evidence on the existence of the symbolic mechanism, which calls for the default inflection if access to the lexical memory is blocked. Thus, this default inflection process works for diminutives as new derived forms in the language. Every noun in MSA has a diminutive form and this derived form is soundfeminine plural inflected regardless of the plural inflection of the non-diminutive form-

In the data in (1), we notice that the nouns in the non-diminutive form may take a broken plural form (for example nahr /?anhaar 'a river/riverss'), while the same nouns in the diminutive form all have the sound feminine inflection. Another supporting example can be seen with the noun jaba/jibaal 'a mountain/mountains', the plural of its diminutive form jubayl is jubay-laat with the suffix -aat across the board added in the plural. 
DATA SET (1):

NOUNS TAKING NON DEFAULT PLURAL FOR NON-DIMINUTIVE FORMS WHILE THEIR DIMINUTIVE FORMS ARE DEFAULT INFLECTED WITH THE -AAT SUFFIX

\begin{tabular}{|c|c|c|c|c|}
\hline $\begin{array}{l}\text { Noun } \\
\text { (nondiminutive Forms) }\end{array}$ & Plural (nondefault) & Diminutive & $\begin{array}{l}\text { Pluralized } \\
\text { Diminutive }\end{array}$ & Gloss \\
\hline nahr & ?anhaar & nuhayr & nuhayr-aat & 'a river' \\
\hline ghuSn & ?aghsaan & ghusayin & ghusayin-aat & 'a branch' \\
\hline manzil & manaazil & munayzil & munayzil-aat & 'a house' \\
\hline lugmah & lugam & lugaymeh & lugaym-aat & 'a piece of food' \\
\hline thi?b & thi?aab & Thu?ayb & thu?ayb-aat & 'a wolf' \\
\hline saqf & ?asguf/suguuf & sugayif & sugayf-aat & 'a ceiling' \\
\hline rajul & rijaal & rujayl & rujayl-aat & 'a man' \\
\hline daar & duur & duwayrah & duwayr-aat & 'a house' \\
\hline baab & ?abwaab & buwayb & buweb-aat & 'a door' \\
\hline naab & ?anyaab/nabaat & nuwayb & nuwyb-aat & 'a fang' \\
\hline thawb & thyaab & thwayb & thweb-aat & 'a dress' \\
\hline Halum & ?aHlaam & Hulaym & Hulaym-aat & 'a dream' \\
\hline Hajar & ?aHjaar & Hujayr & Hujayr-aat & 'a stone' \\
\hline gamar & ?agmaar & guamayr & gumayr-aat & 'the moon' \\
\hline ragheef & ?arghifeh/reghfeh & rughayf & rughayf-aat & 'a loaf' \\
\hline zawraq & zawaarig & zwayrig-aat & zwerig- & 'a boat' \\
\hline Hamuud & 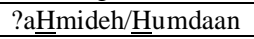 & Humayd & Humayd-aat & 'a pillar' \\
\hline burkaan & baraakeen & buraykeen & buraykeen-aat & 'a volcano' \\
\hline Hasfour & Hasafeer & Husayfeer & Husayfeer-aat & 'a bird' \\
\hline galam & ?aglaam & gulaym & gulaym-aat & 'a pen/pencil' \\
\hline dirham & daraahim & durayhim & durayhim-aat & 'a coin' \\
\hline miftaah & mafaateeh & mufayteeh & mufayteeh-aat & 'a key' \\
\hline mandeel & manadeel & munaydeel & munaydeel-aat & 'a scarf' \\
\hline barmeel & barameel & buraymeel & buraymeel-aat & 'a barrel' \\
\hline shams & shumuus & shumaysah & shumays-aat & 'the sunn' \\
\hline Nakhlah & nakheel/ nakhl & nukhaylah & nukhayl-aat & 'a tree palm' \\
\hline Sanduug & Sanadeeq & Sunaydeeq & Sunaydeeq-aat & 'a box' \\
\hline kalb & kilaab & kulayb & kulab-aat & 'a dog' \\
\hline yad & ?aydi/?ayaadi & yudayah & yuday-aat & a hand' \\
\hline jamal & jimaal & jumayl & jumayl-aat & 'a camel' \\
\hline gandeel & ganadeel & gunaydeel & gunaydeel-aat & 'a candle' \\
\hline misbaaH & maSaabeeH & muSaybeeh & muSaybeeH-aat & 'a light' \\
\hline girtaas & garaatees & guraytees & guraytees-aat & 'stationary' \\
\hline nimir & mumuur & numayr & numayr-aat & 'a tiger' \\
\hline dub & dubab(h) & dubayb & dubayb-aat & 'a bear' \\
\hline minbar & manaabir & munaybeer & munaybeer-aat & 'a speech place' \\
\hline maHrath & maHaarith & muHayrith & muHayrith-aat & 'a gallery' \\
\hline Faanuus & fawaanees & fwaynees & fwaynees-aat & 'a light' \\
\hline jundu & janaadib & junaydeeb & junaydeeb-aat & 'a hopper' \\
\hline
\end{tabular}

In data set (1), there is evidence supporting the predictions proposed by the symbolic accounts that the derived formsdiminutives in particular- all have the sound feminine default form with the combinatorial suffix -aat added to the diminutive to derive the plural form.

\section{B. The Canonical Root Account}

According to the data provided in (1), the emergence of the default inflection for the diminutive forms is marked with the suffix -aat. This default representation is accounted for in terms of the notion of the canonical root. Canonical root can be of considerable importance in the generality of the default inflection to words that have no access to the memory such as borrowings, denominals, names, diminutives, etc. So, the default inflection with -aat is assigned to diminutives which fail to trigger stored associations due to their lack of the canonical root. Marcus (1995) defines the canonical root as "address or distinct identity as a word in the language; a part-of-speech category, subcategory features (e.g., transitive or intransitive for verbs, count or mass for nouns); a semantic representation and phonological representations". A canonical root has the implication that words cannot be represented in the mental lexicon as random collections of information, one of the prominent features of the 'canonical root' is that it has a representation format for these words. McCarthy and Prince (1990) draw attention to the fact that the phonological representation must conform to a canonical template for words in the language. In MSA, canonical roots are marked by their inflection in the plural. For example, the two-syllable words ending with the feminine marker $-a$ take the sound feminine plural (For instance the word majalla/ majall-aat 'a magazine/magazines'). On the other hand, MSA presents instances of noncanonical root words like diminutives. For example, the word singular masculine noun mandeel 'a scarf' has the broken plural manadeel 'scarves' while its derived diminutive form munaydeel 'a small scarf' is default sound feminine inflected as munaydeel-aat 'small scarves'. These noncanonical words may be assigned any plural form due to the lack of access of these categories to their canonical root in the lexicon. In this case, no lexical access exists between the derived word and 
any mental representation; as a result, the sound feminine default comes into play as a default inflection for these derived forms.

\section{Similarity EFFECTS AND DefaUltNeSS}

In this section, we discuss how the similarity effects are modulated by the defaultness of the nouns of diminutive inflection. Both the symbolic and associative hypotheses converge in their view of irregular nondefault inflection as an associative process. Hence, both accounts predict that irregular nondefault inflection should be sensitive to the similarity of the target to its base. Berent (1999) states that while the default inflection is a combinatorial process; it is insensitive to similarity effects. The dissimilarity between the two views concerns regular inflection. If regular inflection is achieved solely by the default mechanism, then it should be insensitive to similarity effects: targets that are highly similar to a regular base should be just as likely to agree with its inflection as highly dissimilar targets. The data in (2) and (3) below provide evidence that the singular diminutive forms are default inflected with the suffix -aat regardless of whether the singular nondiminutive form is inflected with the default marker -aat regularly or with the irregularly inflected singular form. In other words, the noun kitaab 'a book' for example is broken plural inflected as kutub 'books' and the noun mataar 'an airport' is sound feminine inflected as matar-aat 'airports' while their diminutive forms -kutayeb and mutayer- are both default inflected as kutayb-aat and matar-aat respectively. Thus, it is necessary to indicate that the plural of the diminutive form is insensitive similarity effects.

DATA SET (2):

NOUNS THAT ARE NOT SOUND FEMININE PLURAL INFLECTED BUT THEIR DIMINUTIVE COUNTERPARTS ARE

\begin{tabular}{|l|l|l|l|l|}
\hline Noun & Plural onsound feminine & Diminutive form & Plural diminutive & Gloss \\
\hline kitaab & kutub & kutayib & kutayib-aat & 'a book' \\
\hline xaatim & xawaatim & xuwaytim & xuwaytim-aat & 'a ring' \\
\hline jisim & ?ajsam & jusayim & jusaym-aat & 'a body' \\
\hline juzu? & ?jzaa? & juzay? & juzay?-aat & 'a small part' \\
\hline jabal & jibaal & jubayl & jubayl-aat & 'a mountain' \\
\hline
\end{tabular}

DATA SET (3)

NOUNS AS WELL AS THEIR DIMINUTIVE COUNTERPARTS ARE SOUND FEMININE PLURAL INFLECTED

\begin{tabular}{|l|l|l|l|l|}
\hline Noun & Regular Plural & Diminutive form & Plural diminutive & Gloss \\
\hline mataar & matar-aat & mutayr & mautayr-aat & 'an airport' \\
\hline jarraar & jarrar-aat & jurayreer & jurayreer-aat & 'a tractor' \\
\hline muharrik & muharrik-aat & jwhayreek & muhayreek-aat & 'an engine' \\
\hline jawaaz & jawaz-aat & shujayrah & jwayz-aat & 'a passport' \\
\hline shajarah & shajar-aat & thumayrah & shujayr-aat & 'a tree' \\
\hline thamarah & thamar-aat & gurayfah & ghurayf-aat & 'fruit' \\
\hline gurfah & ghurf-aat & wurayqah & wurayq-aat & 'a room' \\
\hline waraqah & ?awr-aaq & wurayd-aat & ' a rose' \\
\hline wardah & ward-aat & waraydah & buqayr-aat & 'a cow' \\
\hline baqarah & baqar-aat & buquayrah & tumayr-aat & 'a piece of date' \\
\hline tamrah & tamar-aat & tumayrah & & \\
\hline
\end{tabular}

In MSA, as shown in the data in $(2 \& 3)$, the diminutive forms for both the nouns that have sound-feminine inflected plural (jarraar/ jarrar-aat 'a tractor') and the words that are non sound-feminine inflected plural (jisim/?ajsam 'a body') take the default form with the sound-feminine plural -aat in all cases of the diminutive derivation. Accordingly, there is no evidence showing similarity effects for the plural inflection of the diminutives of non sound-feminine plural inflected words. Evidence of similarity effects would be observed if the plural inflection of the non-sound feminine inflected nondiminutive forms would be a non sound feminine plural in the plural diminutive, while, on the other hand, the inflection of the sound feminine inflected form would be the default sound feminine plural for the diminutive form. The mapping between the singular and the plural form in this context would be evidence on similarity effects. In both cases, the default inflection applies generally, regardless of the similarity of the targets to stored tokens. Prasada and Pinker (1993) present evidence that the assignment of the default sound feminine plural inflection to non-words that are dissimilar to existing regular verbs does not differ from non-words that are highly similar to familiar regular verbs. Conversely, Kim et al. (1991\& 1994) Marcus et al. (1995) argue that default inflection is observed for borrowings, names and denominals that are highly similar, or even identical to stored irregular words. These findings support the view that regular default inflection is achieved by the symbolic mechanism.

\section{RESUltS AND DISCUSSION}

As far as we can tell, ever since Rumelhart, D.E. and McClelland, J.L. (1986), the representation of defaultness and the mechanism by which it comes into play have been under scrutiny. The questions that this study raised are how defaultness can be represented and in what domains this defaultness can be analyzed crosslinguistically.

The architecture of defaultness in MSA was shown to have a crosslinguistic characteristic. This conclusion was based upon the defaultness definition which refers to the application of the 'elsewhere rule pattern' on non-canonical forms. 
Accordingly, the data taken from MSA offers evidence that the symbolic account is expected to account for the representation of the diminutive forms as having the default form when pluralized. The notion of the canonical root was introduced to account for the emergence of the default for the diminutives in MSA. Default forms are observed as an emergency inflection when lexical access is blocked due to the lack of the canonical root. In the present research, diminutives as new forms in the lexicon of MSA are proved to have no canonical root and thus have the default inflection in the plural with the suffix-aat attached to the singular form of the diminutive regardless of its nondiminutive plural form.

Moreover, insensitivity of defaultness to similarity effects is observed in the inflection of the diminutive forms in MSA. In the data above $(2 \& 3)$ the sound-feminine inflected singular nouns as well as the non sound-feminine inflected singular nouns take the default sound-feminine plural in the diminutive inflection. This type of default inflection confirms the notion of the absence of similarity factors between the sound feminine inflected forms taking the diminutive inflection and the nonsound feminine inflected forms taking the sound feminine default for the diminutive form in MSA. This insensitivity of default inflection -the sound feminine - to similarity effects replicates the English findings provided by Parasada and Pinker (1993) and Hebrew findings investigated by Berent et al (1999). Therefore; this default inflection is accounted for due to the fact that diminutives are categorized as separate entries from their root nouns.

These findings are compatible with the symbolic view in terms of two perspectives: First, the default sound feminine inflection in MSA has the productivity to be extended to any word that does not have a canonical root by a computational mechanism of adding the suffix - aat to the diminutive form. Second, no role of similarity effect is observed between the default sound feminine plural diminutives and their base non-feminine singulars.

\section{REFERENCES}

[1] Berent, I., Pinker, S., \& Shimron, J. (1999). Default nominal inflection in Hebrew: Evidence for mental variables. Cognition, 72, 1-44.

[2] Bybee, J. (1995). Regular morphology and the lexicon. Language and Cognitive Processes, 10, 425-455.

[3] Chomsky, Noam, and Morris Halle. (1968). The sound pattern of English. New York: Harper and Row. Xiv, 470 pages. Reprinted 1991, Boston: MIT Press.

[4] Clahsen, H., Rothweiler, M., Woest, A., Marcus, G. (1992). Regular and irregular Inflection in the acquisition of German noun plurals. Cognition 45, 225-255.

[5] Clahsen, H. (1999). Lexical entries and rules of language: A multi-disciplinary study of German inflection. Behavioral and Brain Sciences 22, 991-1060.

[6] Clahsen, H., Eisenbeiss, S. \& Sonnenstuhl, I. (1997) Morphological structure and the processing of inflected words. Theoretical Linguistics 23, 201-249.

[7] Corbett, G. (1994).Agreement. In R. E. Asher(ed.). Encyclopedia of Language and Linguistics, vol. 1, Oxford: Pergamon Press, 54-60.

[8] Fodor, J., Pylyshyn, Z., (1988). Connectionism and cognitive architecture: a critical analysis. Cognition 28, 3-71.

[9] Hammond, M.(1988)." Templatic Transfer in Arabic Broken Plurals". Natural Languages and Linguistic Theory.6.274-270

[10] Halle, M., Marantz, A., (1993). Distributed Morphology and the pieces of Inflection. Cambridge, MA: MIT Press.

[11] Hare, M., \& Elman, J. (1995). Learning and morphological change, Cognition, 56, 61-98.

[12] Holes, C. (1995). Modern Arabic. London: Longman.

[13] Kim, J, et al., (1991). Why no mere mortal has ever flown out to center field. Cognitive Science 15, 173-218.

[14] Kim, J., Marcus, G., Pinker, S., Hollander, M., Coppola, M., (1994). Sensitivity of children's inflection to grammatical structure. Journal of Child Language 21, 179-209.

[15] Khouloughli, D. -E. (1992). Basic lexicon of Modern Standard Arabic. Paris: Harmattan.18- Kusaci: 1977.Verb, learn, Behav .16, 589.

[16] Levy, M.M, (1971). The Plural of the noun in Modern Standard Arabic .The University of Michigan, Ph.D. Diss.

[17] Marcus, G. F., Pinker, S., Ullman, M., Hollander, M., Rosen, T. \& Xu, F. (1992). Overregularization in language acquisition. Monographs of the Society for Research in Child Development, Serial no. 228, Vol. 57.

[18] Marcus, G., Brinkmann, U., Clahsen. H., Wiese, R., \& Pinker, S. (1995). German inflection: The exception that proves the rule. Cognitive Psychology, 29, 189-256.

[19] Marcus, G., (1998a). Can connectionism save constructivism? Cognition 66, 153-182.

[20] Marcus, G., (1998b). Rethinking eliminative connectionism. Cognitive Psychology (3), 243-282.

[21] McCarthy, J., \& Prince, A. (1990). Foot and word in prosodic morphology: The Arabic broken plural. Natural Language and Linguistic Theory, 8, 209-283.

[22] MacWhinney, B., \& Leinbach, J. (1991). Implementations are not ceptualizations: Revising the verb-learning model. Cognition, 40, 121-157.

[23] Plunkett, K., Marchman, R., (1993). From rote learning to system building: acquiring verb morphology in children and connectionist nets. Cognition 48, 21-69.

[24] Prasada, S., \& Pinker, S. (1993). Generalisation of regular and irregular Morphological patterns. Language and Cognitive Processes, 8, 1-56.

[25] Ratcliffe, R. (1998). The "broken" plural problem in Arabic and comparative Semitic: Allomorphy and analogy in nonconcatenative morphology. Amsterdam. John Benjamins. 
[26] Rumelhart, D.E., McClelland, J.L. (1986). On learning the past tense of English verbs: implicit rules or Parallel distributed processing? In: McClelland, J.L., Rumelhart, D.E., The PDP Research Group (Eds.), Parallel Distributed Processing: Explorations in the Microstructure of Cognition, Vol. 2.

[27] Rumelhart \& J. McClelland (Eds.). (1987). Parallel distributed processing, Vol. 2. Cambridge, MA: MIT Press.

[28] Stemberger, J. P. (1998). Morphology in language production with special reference to connectionism. In A. Spencer and A. M. Zwicky (Eds.), The Handbook of Morphology (428-452). Oxford: Blackwell.

[29] Wright, W. (1995). A grammar of the Arabic language. Cambridge: Cambridge University Press.

[30] Zwicky, A. (1986). The general case: basic form versus default form. Proceedings of the Annual Meeting of the Berkeley Linguistic Society 12:305-314.

Sabri Alshboul specializes in the cross-linguistic study of morphosyntactic representation of "Defaultness". He is also investigating the mechanism of "Grammaticalization" as represented in the morphosyntactic elements in Jordanian Arabic and Modern Standard Arabic.

$\mathrm{He}$ is a member in the higher Jordanian committee for the English Proficiency Test for the graduate Program 2008 through now. And he is also a member in the Graduate Studies English Proficiency Test, The Ministry of Higher Education and scientific research, Amman, August 2009 through now.

Suhail M. Asassfeh is specialized in Teaching English to Speakers of Other Languages, Language Acquisition, Curriculum Development, Instructional Strategies, Developing Academic Writing. Dr. Assasfeh is member in the Association of Professors of English and Translation at Arab Universities (APETAU). He teaches courses like teaching English as a Foreign/ Second Language, Reading, Academic Writing, Technical Writing, Advanced Reading, Advanced Academic Writing, Curriculum Foundations, Instructional Design, Teaching Strategies, Assessment \& Evaluation of Instruction.

Yousef Al shaboul is interested in Family Literacy, Reading, Language Arts, English for Speakers of Other Languages, Qualitative Research Methodology. Dr Alshaboul taught courses like Reading /ESL Minor for Ph.D level at UNT, USA, English Language Curriculum \& Instruction, Yarmouk University, Jordan and English Language and Literature, Yarmouk University. 